\title{
Using the keystone design perforator island flap in large myelomeningocele closure
}

\author{
Cleiton Formentin, MD, ${ }^{1}$ Erion Junior de Andrade, MD,' Leo Gordiano Matias, MD,1 \\ Andrei F. Joaquim, MD, PhD, ${ }^{1}$ Helder Tedeschi, MD, PhD, ${ }^{1}$ \\ Cássio Eduardo Raposo-Amaral, MD, PhD, ${ }^{2}$ and Enrico Ghizoni, MD, PhD ${ }^{1,2}$
}

\begin{abstract}
${ }^{1}$ Neurosurgery Division-Department of Neurology, University of Campinas (UNICAMP); and ${ }^{2}$ Plastic and Craniofacial Institute, Sobrapar Hospital, Campinas, São Paulo, Brazil
\end{abstract}

\begin{abstract}
OBJECTIVE Many repair techniques have been proposed to treat large myelomeningocele (MMC), and although effective in many cases, some of these techniques can be complex and time consuming, with complications such as cerebrospinal fluid (CSF) leakage, flap loss, tip necrosis, and wound dehiscence. The purpose of this study was to analyze cases of large skin defects and the methods applied and to report the outcomes of the keystone design perforator island flap (KDPIF) technique for large MMC closure.

METHODS The authors performed a retrospective review of all neonatal patients who had undergone KDPIF for MMC closure in the period from 2013 to 2018. All patients had a diagnosis of lumbosacral MMC based on obstetric ultrasound. The neurosurgeons and plastic surgeons had selected the cases after concluding that primary closure would be unlikely. The design of the flap is based on the randomly located vascular perforators, creating two identical opposing flaps to fashion a double keystone flap. During wound closure, $V-Y$ advancement of each end of the double flap in the longitudinal axis creates redundancy in the central portion of the flap and reduces the horizontal tension. After discharge, both the neurosurgery and plastic surgery teams followed up all patients, tracking the results with photography.
\end{abstract}

RESULTS No skin flap dehiscence or necrosis, infection, or CSF leakage was detected, proving the reliability of the flap. One of the patients required further surgery for the large skin defects after insufficient intrauterine closure of the MMC and successfully underwent KDPIF treatment. Another patient (14.3\%) had severe neonatal sepsis, which ultimately led to death. A ventriculoperitoneal shunt was required after the skin defect repair in $5(83.3 \%)$ of the 6 surviving patients. Exceptional aesthetic results were achieved for all patients during the follow-up.

CONCLUSIONS The KDPIF technique is based on well-known vascular perforators of the intercostal, lumbar, and gluteal regions. Wound tension is widely distributed by the flap and, as a consequence, relevant tissue bulk, reliable vascularity, and important geometrical versatility are provided. In addition, most of the muscles and fascia are preserved, which is another advantage in terms of minimizing secondary morbidity to local tissue rearrangement. The use of KDPIF closure was successfully shown to be a viable alternative for more complex MMCs that present with large skin defects.

https://thejns.org/doi/abs/10.3171/2019.7.FOCUS19383

KEYWORDS spina bifida; myelomeningocele; perforator flap

$\mathrm{N}$ EURAL tube defects (NTDs) are congenital anomalies of neural development with a broad spectrum of clinical manifestations, with myelomeningocele (MMC) being the most common type of spina bifida aperta. ${ }^{3}$ It results from defective neural tube closure, which is usually concluded within 28 days after conception. ${ }^{27}$ In the United States, the prevalence of NTDs has been reported to be nearly 1 in 1000 live births, and rates are higher for females. $5,6,16$
MMC is related to lifelong disabilities: motor and sensory deficits, limb and spine deformities, bladder and bowel incontinence, and sexual dysfunction. ${ }^{5}$ Concomitant hydrocephalus is highly associated with MMC (85\%$90 \%$ of cases), as are signs and symptoms of brainstem dysfunction due to the presence of Chiari malformation type II. ${ }^{20}$ The Management of Myelomeningocele Study (MOMS) established the role of fetal surgery in patients with spina bifida as it improved their outcomes. The trial's

ABBREVIATIONS CSF = cerebrospinal fluid; KDPIF = keystone design perforator island flap; $M M C=$ myelomeningocele; NTD = neural tube defect; VP = ventriculoperitoneal.

SUBMITTED May 21, 2019. ACCEPTED July 29, 2019.

INCLUDE WHEN CITING DOI: 10.3171/2019.7.FOCUS19383. 
major findings were a considerable reduction in shunt placement within 1 year after fetal surgery, improved neuromotor function, and improved hindbrain herniation following fetal MMC repair compared to those with postnatal repair. ${ }^{1}$

Postnatal early surgical repair of the defect is recommended in order to reduce the mortality rate by preventing cerebrospinal fluid (CSF) leakage and related infections. ${ }^{17}$ In small defects, treatment is readily achieved by primary closing, although severe and large defects can preclude primary closure. ${ }^{2,18}$ Many repair techniques have been proposed to treat large defects including skin grafts, skin flaps, fasciocutaneous flaps, muscle flaps, and musculocutaneous flaps. ${ }^{9,11,15,19}$ Although effective in many cases, some of these techniques can be complex and time consuming, with complications such as CSF leakage, flap loss, tip necrosis, and wound dehiscence. ${ }^{14}$

The purpose of this paper was to review our experience dealing with large skin defects and to report outcomes of the keystone design perforator island flap (KDPIF) technique, a plastic surgery procedure applied in the reconstruction of soft tissue imperfections in many areas of the body, resulting in a very direct and effective cover for the skin and achieving excellent aesthetic results. ${ }^{4} \mathrm{We}$ also revisited the KDPIF technique performed in the closure of large open NTDs and the pertinent anatomy. $8,10,24$

\section{Methods \\ Patients}

We performed a retrospective review of all neonatal patients who had undergone KDPIF for MMC repair in the period from 2013 to 2018. All the patients had a previous diagnosis of lumbosacral MMC based on obstetric ultrasound and were delivered through planned elective Cesarean section at our facility, except for one of the patients who was transferred to our service after being born at another institution. Another patient had undergone open fetal MMC repair at the gestational age of 26 weeks but subsequently had insufficient intrauterine MMC closure, presenting with a large skin defect postnatally as well as a CSF fistula, requiring further surgery with KDPIF. This newborn had a wide defect, and after dissection of the neural placode and dural closure, a skin graft was placed over the MMC defect. The neurosurgeons and plastic surgeons had selected these patients after concluding that primary closure would be unlikely or even impossible and performed reconstruction of the defects with KDPIF during the neonatal period. The patient who was transferred to our service 14 days after birth underwent surgery on his admission day. After hospital discharge, both the neurosurgery and plastic surgery teams followed up all patients, tracking the results with photography.

The following information was obtained retrospectively: patient demographics, characteristics of the MMC defect including the size and highest level of the defect, intraoperative blood transfusion necessity, length of hospital stay, other associated abnormalities, early and late complications, and follow-up.

Note that we do not perform intrauterine procedures at our facility; instead, we refer pregnant women with the selection criteria to a specialized clinical center. Inclusion criteria for intrauterine procedures are as follows: singleton pregnancy, MMC within the T1-S1 level with evidence of hindbrain herniation confirmed by ultrasound, gestational age of 19-26 weeks, and normal karyotype. Exclusion criteria are as follows: uterine anomaly, other fetal anomaly, severe kyphosis, risk of preterm birth, BMI of $35 \mathrm{~kg} / \mathrm{m}^{2}$ or more, and any medical condition that was a contraindication to surgery in the mother. Two children did not meet the criteria for intrauterine closure because of associated severe kyphosis, and the other patients in this study did not meet the criteria because of a delay in referral to a clinical center.

\section{Surgical Technique}

While under general anesthesia, most times with nasal intubation, the patient has the umbilical vein and an additional peripheral vein catheterized. An arterial line is also used for invasive arterial blood pressure measurement. Then, the patient is placed prone with all pressure points padded. Intravenous prophylactic antibiotics (cefuroxime $50 \mathrm{mg} / \mathrm{kg}$ every 12 hours) are administered after birth and routinely maintained for 48 hours after surgery.

The surgical repair starts with careful reconstruction of the neural placode, generally closed with 6-0 Prolene sutures under magnification, always avoiding dermal inclusions. Then, dissection of the dura mater is performed as wide as possible to reconstruct the dural sac to allow freedom of motion of the postneurulated placode and to prevent its adhesion to dura, trying to achieve a good cord/ sac ratio as described by Pang et al. ${ }^{23}$ As regards our study, the two cases with spinal kyphosis were so severe that the extruded neural placode was distorted and extremely thin, and both patients were paraplegic since birth; therefore, the neural placodes were resected, and the dura was closed on the upper part of the defect.

The KDPIF, originally described by Behan in 2003, ${ }^{4}$ is inspired by the architectural keystone of Roman arches and is designed over dermatome segments. It is drawn as two opposing V-Y flaps oriented parallel to the longitudinal axis of the defect but is performed as a single multiperforator fasciocutaneous advancement flap. ${ }^{21,29}$

The design of the flap is based on the randomly located vascular perforators, creating two identical opposing flaps to fashion a double keystone flap (Figs. 1 and 2). The length of the KDPIF is determined by the size of the defect, and the width is defined considering the proportion 1:3 between the defect and the flap. The trapezoid-shaped flap is contoured along the side of the defect with a right angle at the limits of the island flap.

Skin incisions are made on the outline of the flap and are continued through the subcutaneous tissues to lumbar fascia, while the muscle is left intact and used as the lower limit. Blunt dissection is performed to permit mobilization of the soft tissues while advancing the flap and consequently to facilitate approximation of the edges. It is crucial to preserve the integrity of perforators by avoiding dissection beneath the flap. Whenever possible, all cutaneous nerves and superficial veins that also support the island flap should be preserved within the limits of the incision. The deep fascia, located over the muscle, can 


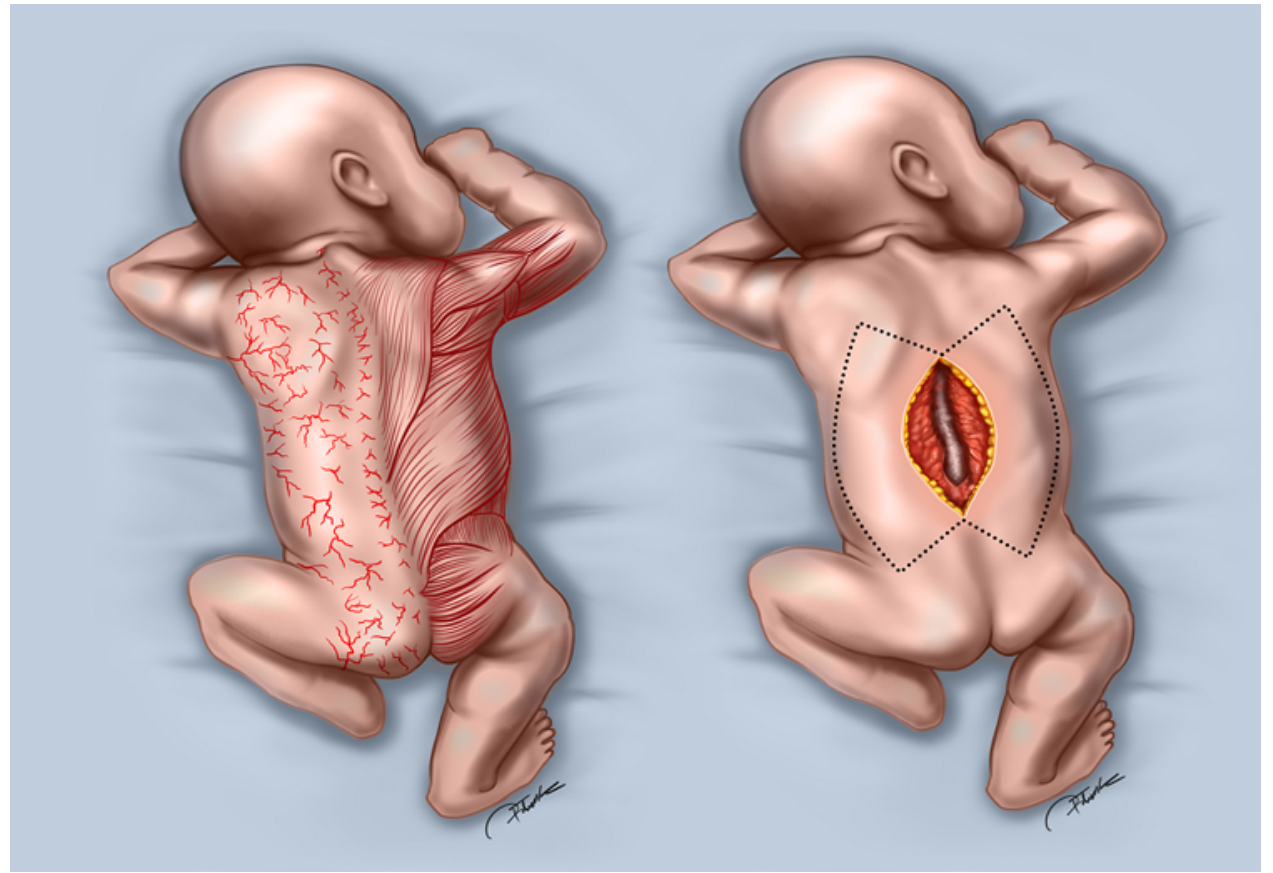

FIG. 1. The opposing flaps were prepared widely, allowing inclusion of as many fasciocutaneous perforators as possible. Left: Areas of the perforator arterial supply on the dorsal trunk are indicated. Right: Curvilinear trapezoidal shape of two opposing keystone flaps that are contoured along both sides of the MMC defect. Copyright Patrick Câmara Braga. Published with permission.

be divided along the outer limit of the flap for larger reconstruction areas, and the edges are undermined through vertical spreading of the fibrous septa, increasing flap mobility while preserving the perforators.

The closure is initially performed by direct apposition of the edges with interrupted single-layer sutures. Then, the V-Y advancement of each end of the double flap in the longitudinal axis is performed to create redundancy in the central portion of the flap and to reduce the horizontal tension.

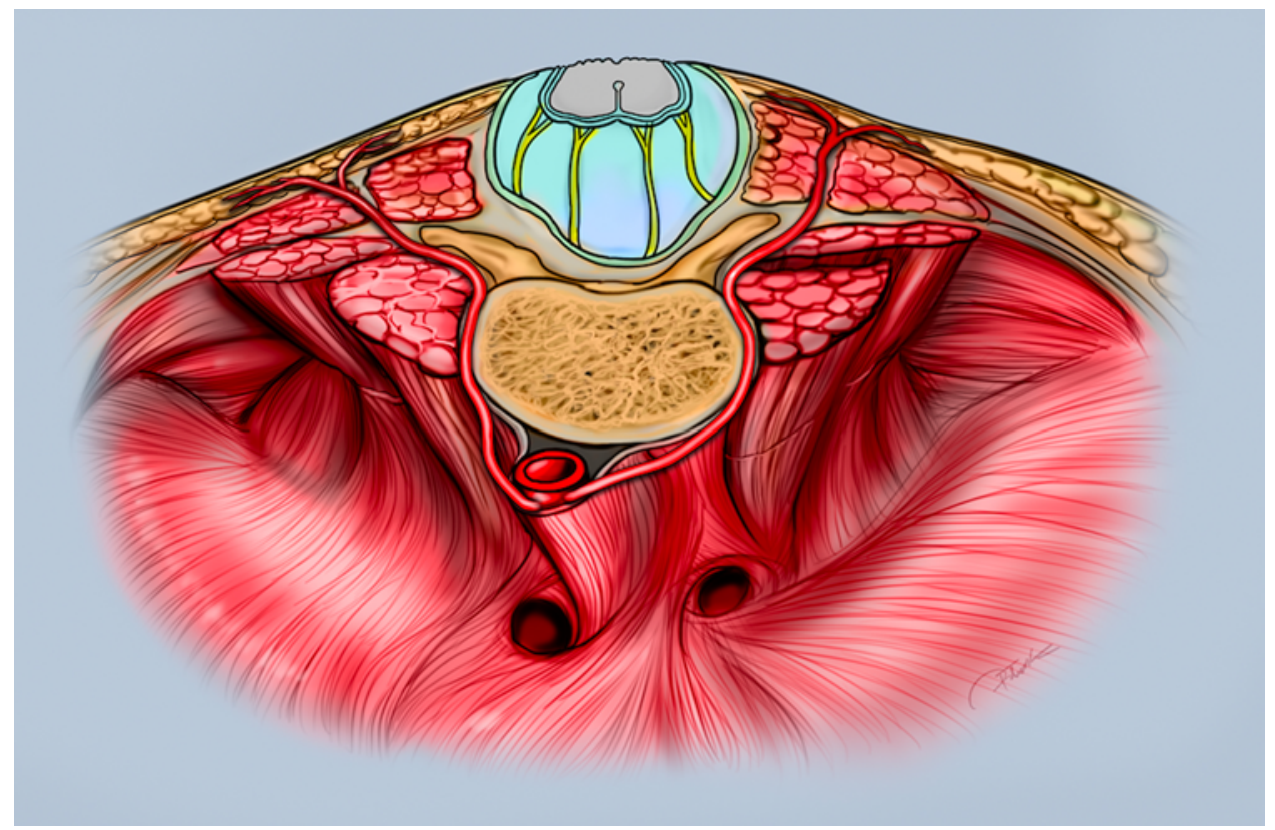

FIG. 2. Lumbar region cross section showing the course of the lumbar arteries and its perforator branches. Copyright Patrick Câmara Braga. Published with permission. 
TABLE 1. Clinical data on 7 patients with MMC treated with KDPIF

\begin{tabular}{ccccccccc}
\hline $\begin{array}{c}\text { Case } \\
\text { No. }\end{array}$ & $\begin{array}{c}\text { Gestation } \\
\text { (wks + days) }\end{array}$ & Sex & $\begin{array}{c}\text { Birth } \\
\text { Weight }(\mathrm{g})\end{array}$ & Mode of Delivery & $\begin{array}{c}\text { Apgar Score } \\
(1 \mathrm{~min} / 5 \mathrm{mins})\end{array}$ & $\begin{array}{c}\text { Age at Op } \\
\text { (days) }\end{array}$ & Hydrocephalus & Other Associated Abnormalities \\
\hline 1 & 40 & M & 2920 & Cesarean section & $8 / 10$ & 1 & Yes & $\begin{array}{c}\text { CM-II, congenital talipes, hypothyroidism } \\
\text { congenital }\end{array}$ \\
\hline 2 & $40+1$ & M & 3850 & Cesarean section & $9 / 10$ & 2 & Yes & $\begin{array}{c}\text { CM-II, interatrial communication, hip } \\
\text { dislocation }\end{array}$ \\
\hline 3 & 40 & M & 3305 & Cesarean section & $9 / 10$ & 14 & Yes & CM-II \\
\hline 4 & 39 & M & 4315 & Cesarean section & $7 / 9$ & 1 & Yes & CM-II, omphalocele \\
\hline 5 & $39+6$ & F & 2450 & Cesarean section & $9 / 9$ & 1 & Yes & CM-II \\
\hline 7 & $37+6$ & F & 3830 & Cesarean section & $8 / 8$ & 1 & Yes & CM-II, congenital talipes \\
\hline 7 & 36 & M & 2450 & Cesarean section & $8 / 10$ & 1 & No & CM-II, rt frontal lobe encephalomalacia, \\
insufficient intrauterine closure of MMC
\end{tabular}

CM-II = Chiari malformation type II.

\section{Hydrocephalus Management: Institutional Protocol}

We do not perform simultaneous MMC repair and shunt placement. We have a rigorous policy regarding this matter in patients with MMC, reserving shunt insertion for those with symptomatic hydrocephalus, severe ventricular dilation, or progressive ventriculomegaly posterior to the defect closure. Following repair, we perform active surveillance to monitor for signs of increased intracranial pressure, assess head circumference, and visualize the ventricles by ultrasonography (every week until head growth has stabilized) to determine if an infant requires ventriculoperitoneal (VP) shunt placement. Although endoscopic third ventriculostomy (ETV) is an alternative to shunt insertion at some centers, because of questions about its effectiveness in the MMC population, we do not perform this procedure for hydrocephalus associated with MMC.

\section{Ethical Considerations}

This study was approved by the local institutional review board (Plastic and Craniofacial Institute, Sobrapar Hospital). All parents provided written informed consent to participate in this retrospective evaluation and for the obtained pictures.

\section{Results}

Five male $(71.4 \%)$ and two female $(28.6 \%)$ patients were delivered by elective Cesarean section. Two cases had concomitant severe spinal kyphosis (28.6\%) associated with MMC where the skin defects were large and precluded primary closure. Demographic data are presented in Table 1.

In our series, wound healing met our expectations: no skin flap dehiscence or necrosis, infection, or CSF leakage was detected. One of the patients $(14.3 \%$, case 4$)$ who had severe kyphosis and other congenital malformations needed a long surgery to remove the extruding bone and developed severe neonatal sepsis, which led to renal insufficiency and death 4 days after the procedure. However, it is worth noting that even after electric shock and high doses of vasoconstrictor drugs, the flap maintained a good aspect without any necrosis or wound breakdown. Immediate flap venous congestion was detected in all patients but resolved within the first week. No other complications were noted in the other patients during the entire follow-up. The mean follow-up was 16.3 months (range 6-56 months). Excellent aesthetic outcomes were achieved (Fig. 3).

Five (83.3\%) of the 6 surviving patients required a VP shunt after the skin defect repair, and the wound was not an issue that would have postponed or precluded shunt insertion. The mean age at VP shunt insertion was 53.6 days (range 7 days -6 months). A summary of the results is presented in Table 2.

\section{Discussion}

Surgical closure of the MMC defect in the early postnatal period is essential to cover the exposed spinal cord and prevent central nervous system infection., ${ }^{2,17}$ Primary repair of a large MMC is challenging because of the significant tissue tension. Also, complications such as wound dehiscence, necrosis, and fistula can be caused by the use of extreme tension to achieve primary closure, which may sometimes require reoperation..$^{28}$

Ozveren et al. selected 32 cases of MMC defects and determined the surgical technique by considering the area of the defect as a percentage of the thoracolumbar region. ${ }^{22}$ In their study, the authors managed to achieve primary closure of the defects occupying less than $8 \%$ of the area of skin in the thoracolumbar region..$^{22}$ Many techniques have been successfully used for reconstruction of an MMC defect that could not be primarily closed, including skin grafts, skin flaps, fasciocutaneous flaps, and muscle flaps..$^{911,15,17}$

We reported our experience using the KDPIF and working with the plastic surgery team. There is dual vascularization of the flap, which is reliable because of the subcutaneous vascular network and muscular perforator supply. ${ }^{26}$ Blunt dissection of the flap margins preserves perforators arising from the underlying muscular tissue and the superficial vascular network. ${ }^{26}$ This technique is based on well-known vascular musculo-/fasciocutaneous perforators of the gluteal and lumbar regions as well as the intercostal perforators. ${ }^{21,26}$ 


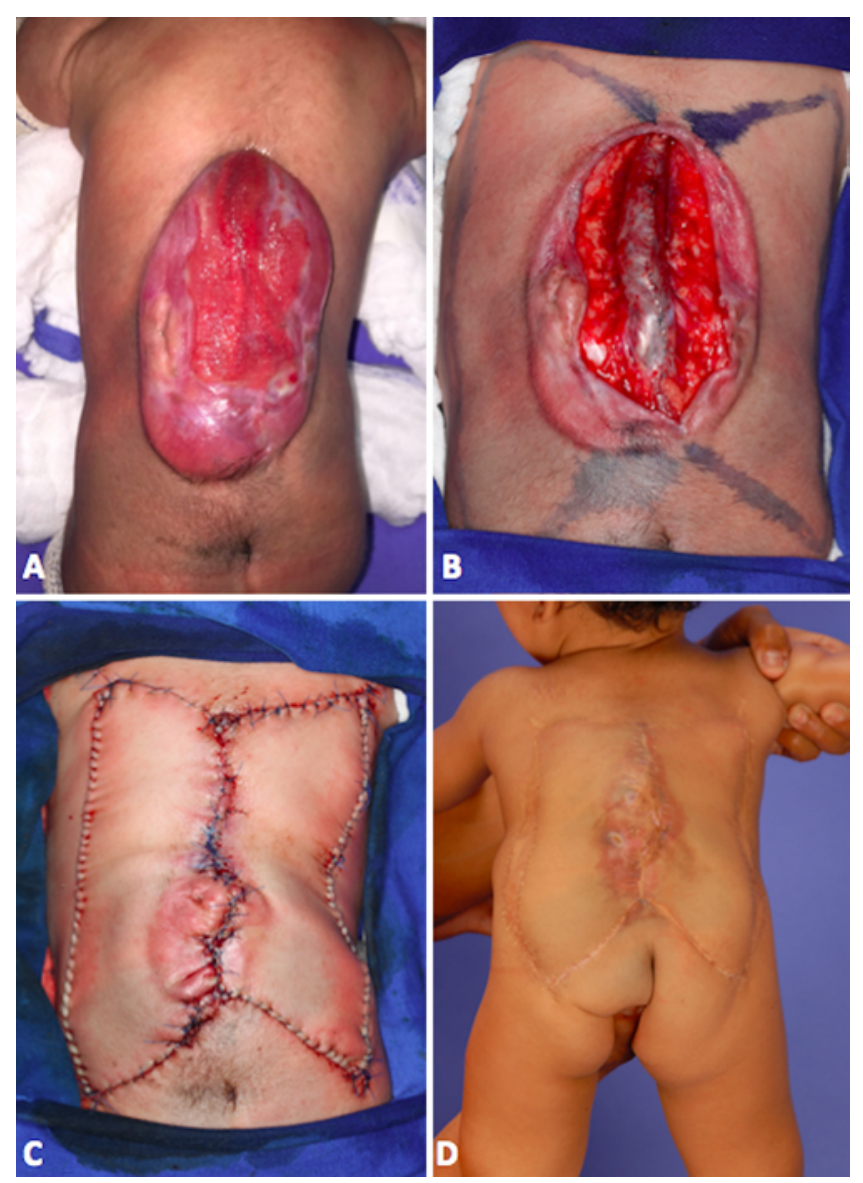

FIG. 3. A: Preoperative photograph showing a large MMC. B: Intraoperative photograph showing the dissection and closure of the dural sac after reconstruction of the neural placode. C: Completed keystone flap repair. D: One year after KDPIF.

The perforator artery originates from the lumbar and intercostal arteries, arising directly from the aorta, at the level of the vertebral body (Fig. 2). ${ }^{12}$ Typically, there are four lumbar arteries on each hemibody, arising from the posterior wall of the aorta with a trajectory just posterior to the psoas major muscle..$^{12,13}$ The upper three arteries travel laterally and backward between the quadratus lum- borum and erector spinae muscles, while the lower pair of arteries usually runs anterior to the quadratus lumborum muscle. ${ }^{12,13}$ Each artery emits a perforating artery just lateral to the erector spinae muscles, sending few branches to the skin. ${ }^{12,13}$

Wound tension is widely distributed by the flap; consequently, relevant tissue bulk, reliable vascularity, and an important geometrical versatility are provided. ${ }^{4,25}$ In addition, most of the muscles and fascia are preserved, which is another advantage in terms of minimizing secondary morbidity to local muscle and soft tissue rearrangement, an issue that is real and of paramount importance in order to prevent belated deformities in this set of patients. One potential disadvantage of this technique is the fact that the place of most tension of the sutures is localized on the midline just above the closed NTD, what in theory could be favorable for CSF leakage. An interesting fact is that none of our cases had postoperative CSF leakage, and we attribute this result to a watertight dural closure.

The impact of fetal closure in MMC is not known and requires further study. Potentially, surgeons can perform fetal repair relatively safely, and the result can be significantly beneficial to the child. With the advent of fetal repair and the expansion of referral centers, we believe that surgical expertise in postnatal closure will be progressively lost. Fetal MMC repair demands a large quantity of fetal surgery centers that include a multidisciplinary team of experts, limiting the number of centers dealing with MMC. Clearly, only a few centers will be eligible to provide such care, and the number of centers dealing with fetal MMC repair must be subjected to analysis considering each area in order to allow sufficient experience and provide the best treatment. Despite the evolution of fetal repair (open vs fetoscopic surgery), selection criteria will probably progress as well and become more restricted to patients who can attain the best results. On the flip side, a referral center for fetal surgery will subsequently decrease surgical expertise on traditional postnatal MMC repair. Additionally, the pediatric neurosurgeon will have to be prepared to deal with some severe congenital skin defects that are not eligible for fetal repair, such as cases of kyphosis (Fig. 4). Finally, some patients who have undergone fetal repair surgery will be born with wound dehiscence, CSF leakage, or a defect just covered with synthetic grafts (most on fetoscopic procedures) that will represent new

TABLE 2. Summary of characteristics of the MMCs and complication data

\begin{tabular}{ccccccccc}
\hline $\begin{array}{c}\text { Case } \\
\text { No. }\end{array}$ & $\begin{array}{c}\text { Length } \times \text { Width } \\
\text { of Defect }(\mathrm{cm})\end{array}$ & $\begin{array}{c}\text { Level of } \\
\text { Lesion }\end{array}$ & Kyphosis & $\begin{array}{c}\text { Blood } \\
\text { Transfusion }\end{array}$ & $\begin{array}{c}\text { Length of Hospital } \\
\text { Stay (days) }\end{array}$ & $\begin{array}{c}\text { Age at VP } \\
\text { Shunt Insertion }\end{array}$ & $\begin{array}{c}\text { Complication } \\
\text { (mos) }\end{array}$ \\
\hline 1 & $12.4 \times 8.5$ & T12-L1 & Yes & Yes & 30 & 10 days & None & 56 \\
\hline 2 & $10.8 \times 7.8$ & L5-S1 & No & No & 33 & 11 days & None & 11 \\
\hline 3 & $22 \times 12.2$ & T10-11 & No & No & 25 & 7 days & None & 24 \\
\hline 4 & $13.2 \times 8.2$ & L1-2 & Yes & Yes & NA & NA & Death & NA \\
\hline 5 & $10.5 \times 7.6$ & L3-4 & No & No & 15 & 6 mos & None & 10 \\
\hline 6 & $9 \times 6.5$ & L4-5 & No & No & 22 & 2 mos & None & 6 \\
\hline 7 & $9.5 \times 7.4$ & L4-5 & No & No & 10 & NA & None & 7 \\
\hline
\end{tabular}

FU = follow-up; $\mathrm{NA}=$ not applicable. 


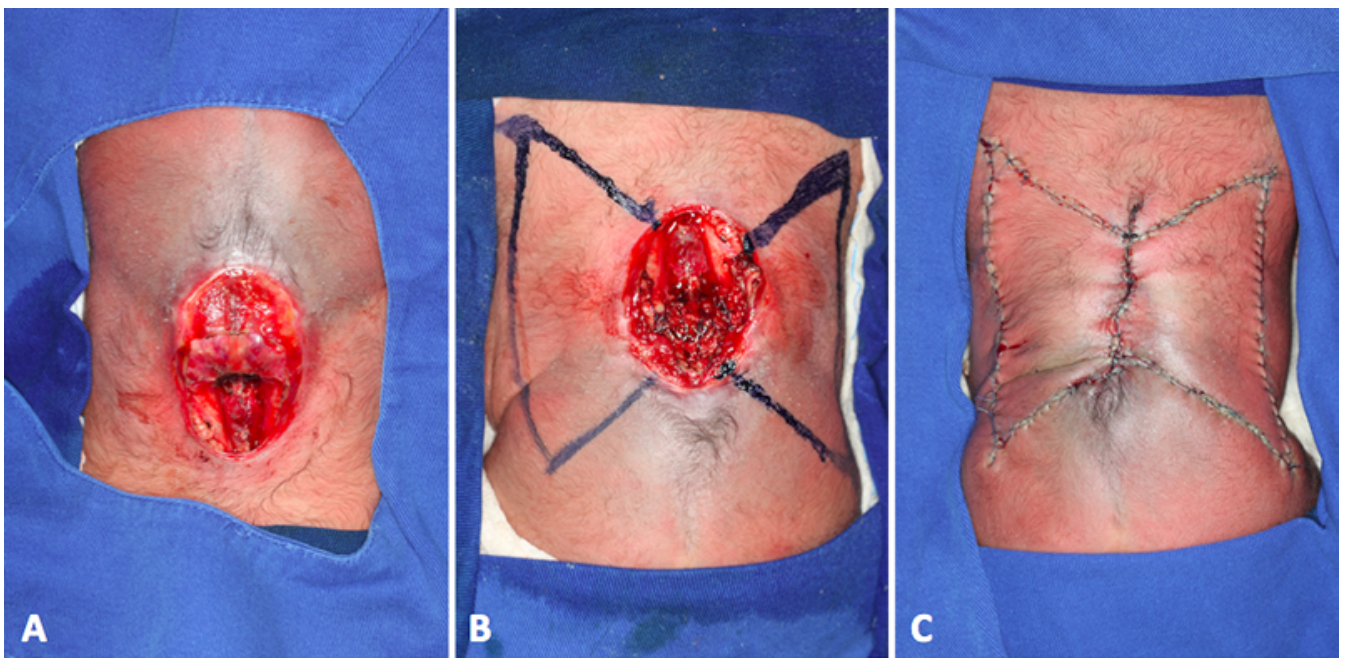

FIG. 4. A and B: Intraoperative photographs of one of the patients with kyphosis associated with a lumbosacral MMC. C: Photograph obtained after dural repair and bilateral KDPIF reconstruction of the defect.

challenges to pediatric neurosurgeons. One of the patients in the present study required further surgery for the large skin defect because of insufficient intrauterine closure of the MMC and successfully underwent KDPIF treatment (Fig. 5). In this context, pediatric neurosurgeons should become familiar with plastic surgery techniques to close large defects and work with plastic surgeons to provide the best treatment for such complex cases.

The technique described is effective and feasible in newborns with complex defects. These patients are very delicate and clinically vulnerable. Therefore, operative time, blood loss, and tissue manipulation are important factors that can influence the outcome. A good example is severe spinal kyphosis where the bone defect precludes skin closure independent of the flap technique chosen. In theses cases, bone removal must be performed to allow appropriate skin closure, which is time consuming and could lead to significant blood loss, requiring the most simple and effective technique to close the skin defect? We applied the KDPIF technique in two cases of kyphosis, and it proved to be very straightforward and successful (no dehiscence or necrosis), although intraoperative blood transfusions were necessary in both cases. However, it is important to note that one of these patients died 4 days after the procedure. The patient had severe kyphosis and omphalocele associated with MMC. He needed a long surgery to remove the extruding bone and developed severe neonatal sepsis and septic shock that led to renal insufficiency and death. The flap maintained a good aspect without any necrosis or wound breakdown. Even though anesthesia and surgical techniques have been improved, neonatal surgery remains a major cause of morbidity and mortality, especially when it comes to this highly vulnerable population of infants.
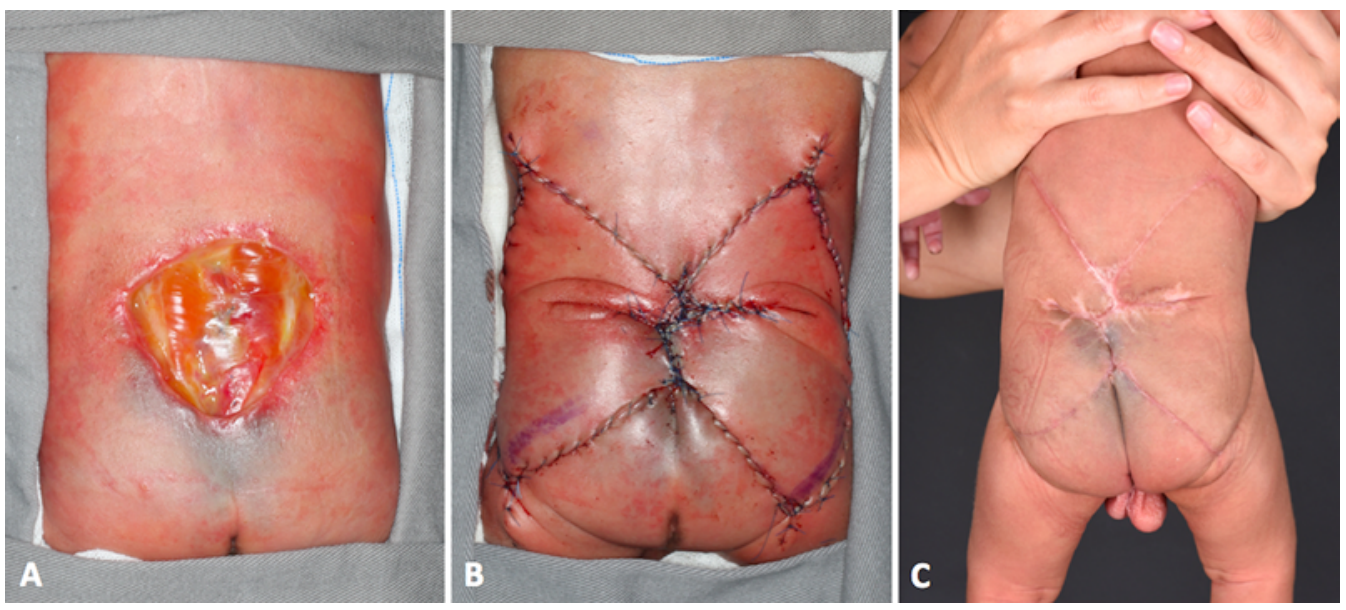

FIG. 5. A: Preoperative photograph of the patient who had insufficient intrauterine closure of the MMC requiring further surgery for the skin defects. B: Intraoperative photograph after KDPIF reconstruction of the defect. C: An excellent aesthetic outcome was achieved by the 3-month follow-up. 
Another issue that is important to highlight here is the need for teamwork in conjunction with plastic surgeons (C.R.A.). This partnership is paramount in order to deal with large defects and wound problems (venous congestion, dehiscence, necrosis, and infections). As stated above, young pediatric neurosurgeons will be faced with large and complex open NTDs without being trained on the simple ones as well as newborns with wound dehiscence and CSF fistula following fetal repair. We strongly believe that a team effort between pediatric neurosurgeon and plastic surgeon is the key to offering the most outstanding treatment for these complex cases, as in craniofacial surgery. All of our cases were planned and operated on in conjunction with the plastic surgery team, and the patients are being followed up for life by both teams; these strategies reflect optimal care and a high level of parent satisfaction.

\section{Conclusions}

In the era of fetal repair for open NTDs, pediatric neurosurgeons dealing with postnatal repair will face challenging cases and must be prepared to manage them. KDPIF proved to be a relatively simple, successful, and safe technique that can be performed to close complex congenital defects. Performing the technique in conjunction with plastic surgeons can be the standard of care for postnatal repair of such defects, once the team becomes familiar with it. The team effort of the pediatric neurosurgeon and plastic surgeon will certainly provide the best results for patients and their families.

\section{References}

1. Adzick NS, Thom EA, Spong CY, Brock JW III, Burrows PK, Johnson MP, et al: A randomized trial of prenatal versus postnatal repair of myelomeningocele. N Engl J Med 364:993-1004, 2011

2. Atik B, Tan O, Kiymaz N, Yilmaz N, Tekes L: Bilobed fasciocutaneous flap closure of large meningomyeloceles. Ann Plast Surg 56:562-564, 2006

3. Au KS, Ashley-Koch A, Northrup H: Epidemiologic and genetic aspects of spina bifida and other neural tube defects. Dev Disabil Res Rev 16:6-15, 2010

4. Behan FC: The keystone design perforator island flap in reconstructive surgery. ANZ J Surg 73:112-120, 2003

5. Botto LD, Moore CA, Khoury MJ, Erickson JD: Neural-tube defects. N Engl J Med 341:1509-1519, 1999

6. Cragan JD, Roberts HE, Edmonds LD, Khoury MJ, Kirby RS, Shaw GM, et al: Surveillance for anencephaly and spina bifida and the impact of prenatal diagnosis-United States, 1985-1994. MMWR CDC Surveill Summ 44:1-13, 1995

7. Crawford AH, Strub WM, Lewis R, Gabriel KR, Billmire DA, Berger T, et al: Neonatal kyphectomy in the patient with myelomeningocele. Spine (Phila Pa 1976) 28:260-266, 2003

8. Gutman MJ, Goldschlager T, Fahardieh RD, Ying D, Xenos C, Danks RA: Keystone design perforator island flap for closure of myelomeningocele. Childs Nerv Syst 27:14591463, 2011

9. Hayashi A, Maruyama Y: Bilateral latissimus dorsi V-Y musculocutaneous flap for closure of a large meningomyelocele. Plast Reconstr Surg 88:520-523, 1991

10. Jamjoom H, Alnoman H, Almadani Y: Closure of a large thoracolumbar myelomeningocele using a modified bilateral keystone flap. Plast Reconstr Surg Glob Open 4:e1114, 2016
11. Kankaya Y, Sungur N, Aslan OC, Ozer K, Ulusoy MG, Karatay M, et al: Alternative method for the reconstruction of meningomyelocele defects: V-Y rotation and advancement flap. J Neurosurg Pediatr 15:467-474, 2015

12. Kato H, Hasegawa M, Takada T, Torii S: The lumbar artery perforator based island flap: anatomical study and case reports. Br J Plast Surg 52:541-546, 1999

13. Kiil BJ, Rozen WM, Pan WR, Grinsell D, Ashton MW, Corlett RJ, et al: The lumbar artery perforators: a cadaveric and clinical anatomical study. Plast Reconstr Surg 123:1229-1238, 2009

14. Lanigan MW: Surgical repair of myelomeningocele. Ann Plast Surg 31:514-521, 1993

15. Lapid O, Rosenberg L, Cohen A: Meningomyelocele reconstruction with bilobed flaps. Br J Plast Surg 54:570572,2001

16. Lary JM, Edmonds LD: Prevalence of spina bifida at birth-United States, 1983-1990: a comparison of two surveillance systems. MMWR CDC Surveill Summ 45:15-26, 1996

17. Laurence KM: Effect of early surgery for spina bifida cystica on survival and quality of life. Lancet 1:301-304, 1974

18. Lien SC, Maher CO, Garton HJ, Kasten SJ, Muraszko $\mathrm{KM}$, Buchman SR: Local and regional flap closure in myelomeningocele repair: a 15-year review. Childs Nerv Syst 26:1091-1095, 2010

19. Luce EA, Walsh J: Wound closure of the myelomeningocoele defect. Plast Reconstr Surg 75:389-393, 1985

20. Mattogno PP, Massimi L, Tamburrini G, Frassanito P, Di Rocco C, Caldarelli M: Myelomeningocele repair: surgical management based on a 30-year experience. Acta Neurochir Suppl 124:143-148, 2017

21. Mohan AT, Sur YJ, Zhu L, Morsy M, Wu PS, Moran SL, et al: The concepts of propeller, perforator, keystone, and other local flaps and their role in the evolution of reconstruction. Plast Reconstr Surg 138:710e-729e, 2016

22. Ozveren MF, Erol FS, Topsakal C, Tiftikci MT, Akdemir I: The significance of the percentage of the defect size in spina bifida cystica in determination of the surgical technique. Childs Nerv Syst 18:614-620, 2002

23. Pang D, Zovickian J, Oviedo A: Long-term outcome of total and near-total resection of spinal cord lipomas and radical reconstruction of the neural placode: part I-surgical technique. Neurosurgery 65:511-529, 2009

24. Park HS, Morrison E, Lo C, Leong J: An application of keystone perforator island flap for closure of lumbosacral myelomeningocele defects. Ann Plast Surg 77:332-336, 2016

25. Pelissier P, Gardet H, Pinsolle V, Santoul M, Behan FC: The keystone design perforator island flap. Part II: clinical applications. J Plast Reconstr Aesthet Surg 60:888-891, 2007

26. Pelissier P, Santoul M, Pinsolle V, Casoli V, Behan F: The keystone design perforator island flap. Part I: anatomic study. J Plast Reconstr Aesthet Surg 60:883-887, 2007

27. Sadler TW: Mechanisms of neural tube closure and defects. Ment Retard Dev Disabil Res Rev 4:247-253, 1998

28. Savacı N, Güney Ö, Erongun U: Tissue expander application in giant meningomyelocele cases. Turk Neurosurg 4:157160,1994

29. Tenekeci G: Perforator flaps: principles and techniques, in $\mathrm{Amr} \mathrm{S}$ (ed): Issues in Flap Surgery. London: IntechOpen, 2018, pp 37-49

\section{Disclosures}

The authors report no conflict of interest concerning the materials or methods used in this study or the findings specified in this paper. 


\section{Author Contributions}

Conception and design: Formentin, Joaquim, Raposo-Amaral, Ghizoni. Acquisition of data: Formentin, de Andrade. Analysis and interpretation of data: Formentin, Matias, Joaquim, Tedeschi, Ghizoni. Drafting the article: Formentin, de Andrade, Matias, Joaquim, Raposo-Amaral, Ghizoni. Critically revising the article: Formentin, Joaquim, Tedeschi, Raposo-Amaral, Ghizoni. Reviewed submitted version of manuscript: all authors. Approved the final version of the manuscript on behalf of all authors: Formentin. Study supervision: Ghizoni.

\section{Supplemental Information}

\section{Previous Presentations}

Portions of this work were presented in abstract form as proceedings at the XIII Brazilian Congress of Pediatric Neurosurgery,
Fortaleza, Brazil, 2019 (Child's Nervous System, 2019); and at the VIII Congreso Latinoamericano de Neurocirugía Pediátrica, San José, Costa Rica, 2019.

\section{Correspondence}

Cleiton Formentin: University of Campinas, São Paulo, Brazil. cleitonformentin@gmail.com. 